\title{
マルチスケールー方向 GFRP の作製および機械的性毁評価
}

\author{
名取 純希 ${ }^{* 1}$, 川田 宏之 ${ }^{* 2}$
}

\section{Fabrication of multi-scale unidirectional GFRP and characterization of its mechanical properties}

\author{
Junki NATORI ${ }^{* 1}$ and Hiroyuki KAWADA ${ }^{* 2}$ \\ ${ }^{* 1}$ Graduate School of Waseda University Dept. of Applied Mechanics \\ Okubo 3-4-1, Shinjyuku-ku, Tokyo, 169-8555 Japan \\ ${ }^{* 2}$ Waseda University Dept. of Applied Mechanics and Aerospace Engineering \\ Okubo 3-4-1, Shinjyuku-ku, Tokyo, 169-8555 Japan
}

\begin{abstract}
Carbon nanotubes (CNTs) grafted on the fiber surface improves fiber/matrix interfacial adhesion, and form the CNT-resin local composite around each fiber. This study reports the fabrication method of CNT-grafted unidirectional glass fiber reinforced plastics (GFRP) and their mechanical properties. In this study, CNTs were grafted on the T-glass fiber surface using thermal chemical vapor deposition (CVD) at $750^{\circ} \mathrm{C}$. First, quality of grafted CNTs and the mechanical properties of T-glass fiber were evaluated. From the results of investigations and analyses, CNTs grafted onto the fiber surface had relatively-many defects, but were uniform and dense. Moreover, mechanical properties of CNT-grafted T-glass fiber decreased drastically compared with as-received fiber. This degradation was caused by the relaxation of thermal residual stress at fiber surface. Finally, static tensile test were performed to investigate the tensile properties of GFRP. According to static tensile test, it was revealed that fracture strain of CNT-grafted GFRP was decreased by $80 \%$ compared with as-received one, and it showed brittle fracture. This fracture was mainly due to the degradation of fiber strength and the improvement of fiber/matrix adhesion.
\end{abstract}

Key Words : Composite Material, Interface, Molding Methods

\section{1. 精}

カーボンナノチューブ (Carbon nanotube: CNT) は優れた機械的・熱的・電気的性質を有することから FRP の 次世代の強化材，充填材としての適用が期待されている材料である. 中でも CNT 新たな FRP の界面接着方法 として瀻維表面に析出させる試みが考案されている. この方法では, CNT 析出部に樹脂が含浸することでアンカ 一効果を生み出し，従来の処理剤を用いる方法と比較し高い界面せん断強度（Interfacial Shear Strength: ISS）が得 られることが報告されている(1).

本研究室においても，2011 年度佐藤慎也ら ${ }^{(2)}$ は CNT を析出させた T ガラス繊維のモード II の界面特性ついて 調查を行った. その結果, CNT を析出させた場合はそうでない試験片と比較し ISS が約 $68 \%$ 上昇することを確認 した. しかし, 過去の研究は単繊維を埋蔵したモデル試験片であり, 実際に用いられる FRP の CNT の影響に 関する研究は行われていない.

そこで, 本研究では CNT 析出 T ガラス繊維を繊維束の形で樹脂中に埋蔵し，マルチスケール一方向 GFRP を 作製し，その機械的性質について調査を行った．特に，FRP の疲労特性に対し上述した CNT 析出繊維の高い ISS が与える影響について調査することを目的とする．まず，T ガラス繊維束に析出した CNT を走査型電子顕微鏡 (Scanning Electric Microscope: SEM）を用いて観察し，CNT 析出状態について調查した. また，T ガラス繊維の

\footnotetext{
${ }^{* 1}$ 早稲田大学 大学院（广169-8555 東京都新宿区大久保 3-4-1）

*2 正員, 早稲田大学 (广169-8555 東京都新宿区大久保 3-4-1)

E-mail: e-casino.walk15@akane.waseda.jp
} 
機械的性質に対する CNT 析出の影響を調査するため単繊維引張試験を実施した. 次に，マルチスケール一方向 GFRP を作製し，静的引張試験を実施することで CNT 析出による GFRP の機械的性質について調査した.

\section{CNT 析出条件}

本研究では強化繊維に耐熱性に優れる T ガラス繊維を, T ガラス表面への CNT 析出には化学気相成長 (Chemical Vapor Deposition: CVD）法を用いて行った. 表 1 にCNT 析出条件を，表 2 に析出物をラマン分光分析したピーク 值を, 図 1 にラマンスペクトルを、図 2 に T ガラス繊維束に析出した CNT の SEM 観察写真を示す. なお, 図中 に繊維束に対する CNT の重量比を併記し, 括弧内はその標準偏差である.

Table 1 CNT grafting condition.

\begin{tabular}{c|c|c|c}
\hline \hline Ferrocene $\mathrm{g}$ & Ethanol $\mathrm{g}$ & Grafting temperature ${ }^{\circ} \mathrm{C}$ & Grafting time min \\
\hline 0.2 & 1.2 & 750 & 10 \\
\hline
\end{tabular}

Table 2 Raman peak values.

\begin{tabular}{c|c}
\hline \hline D band cm & $-1,431(1.09)$ \\
\hline $\mathrm{G} \mathrm{band} \mathrm{cm}^{-1}$ & $1,664(5.80)$ \\
\hline $\mathrm{G}^{\prime}$ band cm & -1 \\
\hline G/D ratio & $2,764(3.04)$ \\
\hline
\end{tabular}

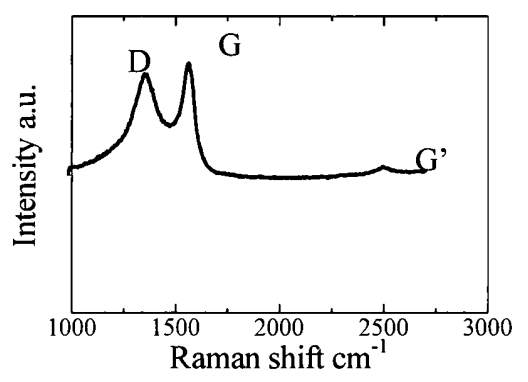

Fig. 1 Raman spectra of grafted CNT.

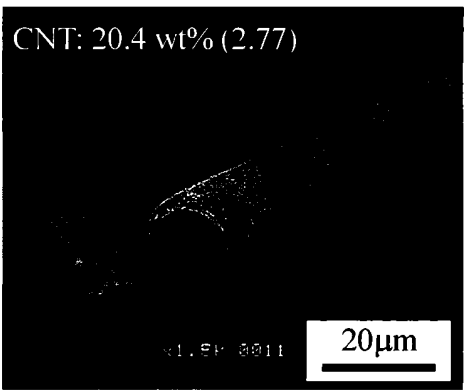

(b) High magnification $(\times 1,500)$

(a) Low magnification $(\times 500)$

Fig. 2 SEM images of CNT grafted T-glass fiber bundle.

表 2 より，今回の CVD 条件における析出物は D バンド， G バンドに加えわずかに G'バンドが確認されたことか ら CNT であるといえる. しかし，G/D 比が小さいことからこの CNT は欠陥が多いことが示唆された. また，図 2 より, 本研究で用いる CVD 条件では T ガラス繊維束に対してほぼ均一かつ高密度に CNT が析出していること がわかる.また，CNTは20.4wt\%となった。

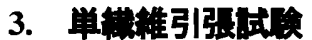

本研究で用いる $\mathrm{T}$ ガラス䋐維は耐熱性に優れるが, $\mathrm{CNT}$ 析出条件である $750^{\circ} \mathrm{C}$ 環境に曝されることで強度が大 幅に低下することが報告されている. そこで, 本試験ではまま材と比較し, CNT 析出繊維 CNT の機械的性質が どの程度低下するかを調査するため, T ガラス単繊維引張試験を実施した．本試験は JIS R 7606 を参考に，試験

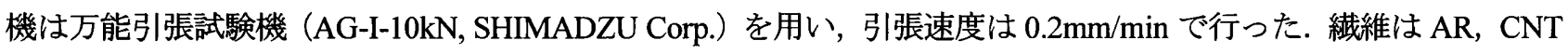
および HT(熱処理)の 3 種類とし, 得られた結果より繊維の機械的性質をワイブル分布を用いて評価する. 表 3 に 各条件における機械的性質を，図 3 にワイブル分布を示す.なお，表中括弧内は標準偏差である. 
Table 3 Weibull parameters and mechanical properties for each condition.

\begin{tabular}{c|c|c|c}
\hline \hline $\begin{array}{c}\text { Shape parameter } \\
m\end{array}$ & 8.92 & 3.47 & 3.47 \\
\hline $\begin{array}{c}\text { Scale parameter } \\
\sigma_{0} \mathrm{MPa}\end{array}$ & 3,669 & 2,468 & 742 \\
\hline $\begin{array}{c}\text { Elastic modulus } \\
E \mathrm{GPa}\end{array}$ & $\begin{array}{c}75.9 \\
(7.26)\end{array}$ & $\begin{array}{c}76.8 \\
(8.60)\end{array}$ & $\begin{array}{c}76.4 \\
(8.43)\end{array}$ \\
\hline $\begin{array}{c}\text { Fracture strain } \\
\varepsilon_{\mathrm{o}} \%\end{array}$ & $\begin{array}{c}4.58 \\
(0.64)\end{array}$ & $\begin{array}{c}2.80 \\
(0.81)\end{array}$ & $\begin{array}{c}0.83 \\
(0.24)\end{array}$ \\
\hline
\end{tabular}

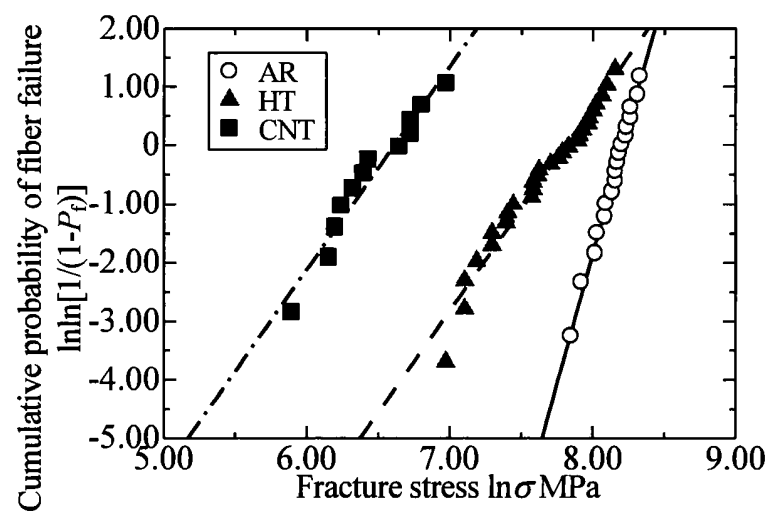

Fig. 3 Weibull plots for each condition.

これより, HT およびCNT の弾性率 $E$ 以外の機械的性質は AR と比較し大幅に低下することを確認した. これは 高温 $\left(750^{\circ} \mathrm{C}\right)$ 環境に繊維が曝されたことで䋐維表面の圧縮残留応力が緩和したこと，界面処理剂が揮発し水分に よるダメージを受けやすくなったこと，繊維表面のき裂が露出したためであると考えられる．また，CNTについ ては CNT 析出時に鉄粒子が繊維に付着することで䋐維表面に傷が発生した可能性や，析出した CNT が絡まるこ とで CNT のはく離による繊維表面への傷の発生などが原因であると考えられる.

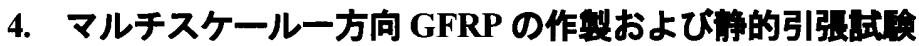

本研究では CNT 析出の析出したマルチスケール一方向 GFRP の作製およびその機械的性質を取得するため, 熱収縮チューブを用いた試験片作製について検討した．表 4 にエポキシ樹脂の配合比を，図 4 に試験片寸法を示 す．試験片は熱収縮チューブに繊維束を挿入後，エポキシ樹脂を封入して作製した．作製した試験片の繊維体積

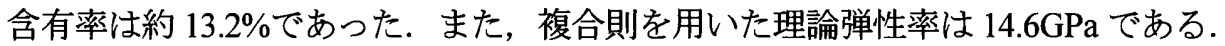

Table 4 Compounding ratio of epoxy resin.

\begin{tabular}{c|c|c}
\hline \hline & Material & $\begin{array}{c}\text { Compounding } \\
\text { ratio }\end{array}$ \\
\hline Base resin & jER828 & 100 \\
\hline Curing agent & jER cure 113 & 32 \\
\hline
\end{tabular}

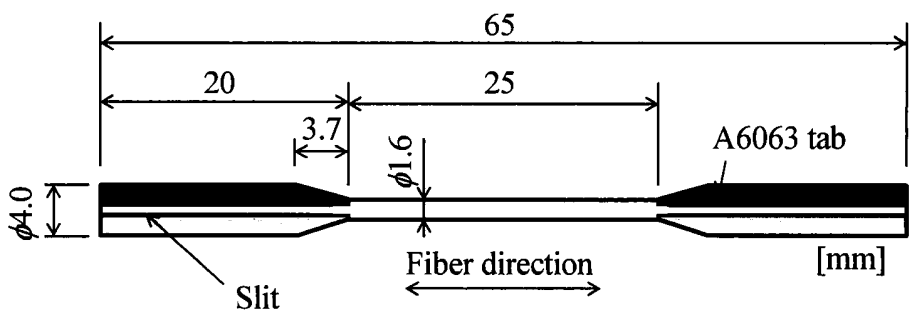

Fig. 4 Geometry of specimen.

作製した一方向 GFRP の機械的性質を調查するため，静的引張試験を実施した．試験機は万能引張試験機 (AG-I-10kN, SHIMADZU Corp.) を用い，引張速度は前章を同様 $0.2 \mathrm{~mm} / \mathrm{min}$ で行った。 また，試験片の種類も AR, HT, CNT の 3 種類とした. なお, 試験片の歪みはひずみゲージ (KFG-1N-120-C1, Kyowa Electronic Instruments CO., LTD）を用いて取得した. 表 5 に各条件における機械的性質を，図 5 に代表的な応力ひずみ線図を，また， 試験本数は AR が 2 本，HT および CNT が各 1 本である.

Table 5 Mechanical properties of unidirectional GFRP.

\begin{tabular}{c|c|c|c}
\hline \hline & AR & HT & CNT \\
\hline $\begin{array}{c}\text { Fracture stress } \\
\sigma_{\mathrm{f}} \mathrm{MPa}\end{array}$ & 390 & 268 & 62.4 \\
\hline $\begin{array}{c}\text { Elastic modulus } \\
E \mathrm{GPa}\end{array}$ & 15.1 & 17.8 & 11.0 \\
\hline $\begin{array}{c}\text { Fracture strain } \\
\varepsilon_{\mathrm{b}} \%\end{array}$ & 2.80 & 1.49 & 0.57 \\
\hline
\end{tabular}

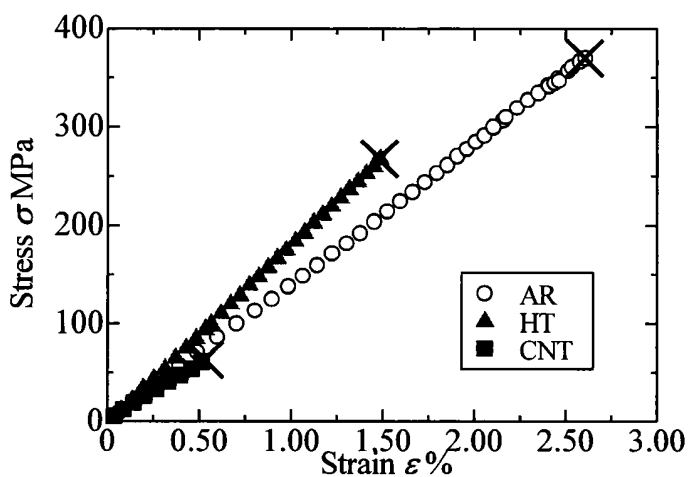

Fig. 5 Stress-strain curves of unidirectional GFRP specimen. 
試験結果より，まず，複合則で算出した弾性率 $E$ と各条件を比較すると，AR は近い值を示しているが，HT は高 く CNT は低い值を示していることがわかる.これらの值については現在調査中であるが，今後試験本数を増や すことで改善されると考えられる．次に，破断ひずみ存について各条件を比較する. AR と HT を比較するとょ は約 47\%低下しており，単繊維引張試験で得られた結果（約 39\%低下）より大きな低下率を示していることがわ かる.これは熱による繊維の強度低下に加え, 界面処理剤を除去したことで䋊維/樹脂界面の接着が不十分となり, 応力伝達が十分に行われていなかったためであると考えられる. AR と CNT 比較すると, 同様に $\varepsilon_{\mathrm{b}}$ は約 $80 \%$ の 低下を示していることがわかる（単繊維引張試験では約 82\%の低下）。これは HT と同様に熱による強度低下に加 え，CNT 析出により ISS が大幅に上昇したことによりぜい性的な破断が発生してしまったと考えられる.

一方向 GFRP の破壊形態にCNT が与える影響を調查し，図 6 に示す.

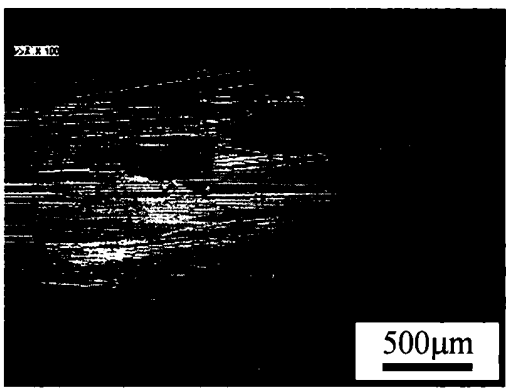

(a) AR (side view)

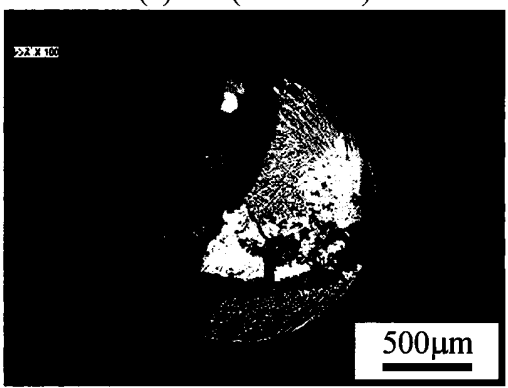

(d) AR (front view)

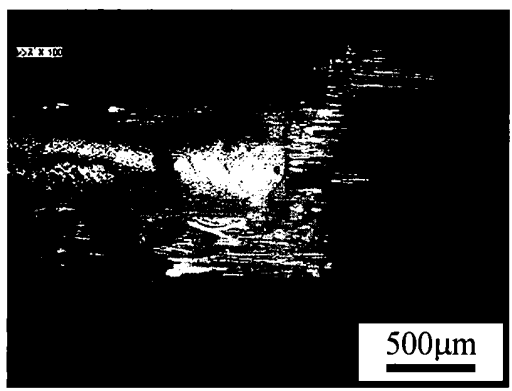

(b) HT (side view)

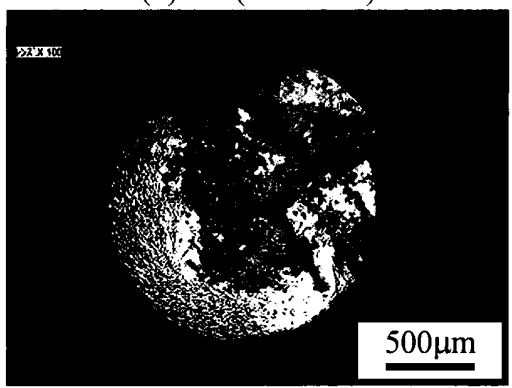

(e) HT (front view)

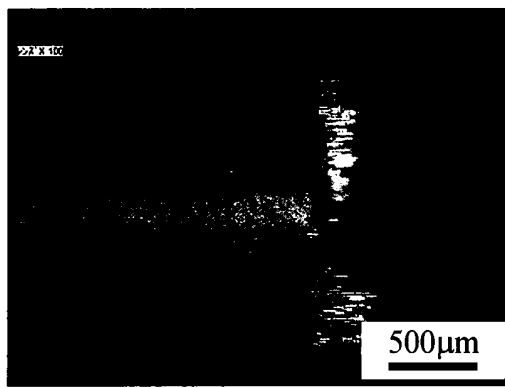

(c) CNT (side view)

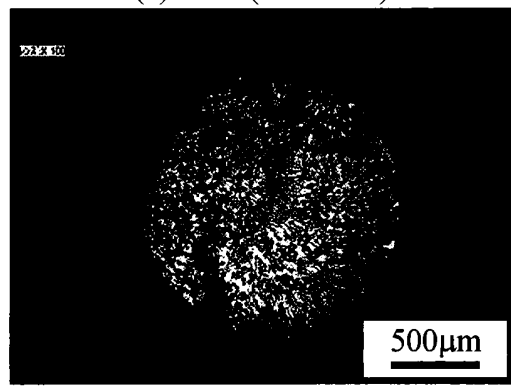

(f) CNT (front view)

Fig. 6 Fracture surface of unidirectional GFRP after static tensile test.

これより，AR および HT は繊維の引抜破壊が発生しているのに対し， CNT では繊維の引き抜けはほとんどな く，ぜい性的な破壊をしていることがわかる．これは CNT によって界面はく離による瀻維/樹脂間の応力緩和が 抑制されたためであると考えられえる. また，AR および HT は試験片断面に均一に繊維が分散せず，樹脂を起点 としき裂が進展していることを確認した.これより試験片作製についても今後検討する必要があると考えられる.

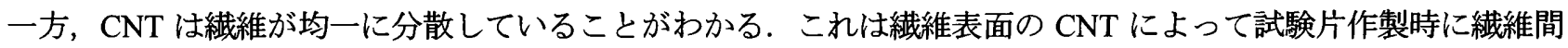
距離が離れたためであると考えられる.

\section{5. 結}

本研究では CNT 析出繊維束を用いたマルチスケールー方向 GFRP を作製し，その機械的性質を評価すること を目的とした. 単繊維引張試験より，T ガラス絨維は CVD 法による熱による影響を大きく受け, 機械的性質が大 幅に低下することを確認した. 静的引張試験より, マルチスケール一方向 GFRP は強化繊維の強度低下と CNT 析出による高い ISS によりぜい性的な破壊を引き起こすことが示唆された．また，試験片作製に関しても瀻維が 樹脂中に均一分散する方法を確立する必要があることが示唆された.

\section{文盛}

(1) Qian, H., Bismarck, A., Greenhalgh, E. S., Kalinka, G and Shaffer, M. S. P., "Carbon nanotube grafted silica fibres: Characterising the interface at the single fibre level”, Composites Science and Technology, Vol. 51, No. 1 (2010), pp. 393-399.

(2) 佐藤慎也, “CNTs 析出 T ガラス繊維/エポキシ樹脂複合材料における界面強度の定量的評価”, 早稲田大学 2011 年 度修士論文. 